\title{
Diffusion Modelling on the Microstructure Evolution in MCrAIY- Superalloy System
}

\author{
Zhenyuan Xu $\mathrm{Xu}^{1,2,3} \cdot$ Kang Yuan ${ }^{1,2,3} \cdot$ Zhaoran Zheng ${ }^{1,2,3} \cdot$ Haoran Peng ${ }^{1,2,3} \cdot$ \\ Jianming Liu ${ }^{1,2,3}$
}

Submitted: 28 August 2020/in revised form: 18 December 2020/Accepted: 19 December 2020/Published online: 20 January 2021 (C) ASM International 2021

\begin{abstract}
Elemental diffusion drives the microstructure development in the MCrAlY-superalloy systems at high temperature. In this paper, two diffusion models were built to simulate the diffusion behavior of elements in the coating or in the coating-substrate system. Firstly, a coreshell model was set up to investigate the thermodynamic and kinetic behavior of the localized microstructure. The results of the simulation successfully explained the mechanism of the formation of $\alpha$ (core) $-\gamma^{\prime}$ (shell) structure at lower temperature $\left(750^{\circ} \mathrm{C}\right)$ and $\gamma$ (core) $-\beta$ (shell) structure at higher temperature $\left(1100{ }^{\circ} \mathrm{C}\right)$. Secondly, a coatingsubstrate planner model was used to simulate the interdiffusion of elements between the MCrAlY coating and the superalloy substrate. The simulation results in the Ni22Cr10AlY-superalloy system semiquantitatively agreed with the experimental observation. Furthermore, by applying the planner diffusion model, the effect of the MCrAlY coatings on the formation of TCP phases in the
\end{abstract}

This article is an invited paper selected from abstracts submitted for the 2020 International Thermal Spray Conference, ITSC2020, that was to be held from June 10-12, 2020, in Vienna, Austria. The conference was canceled due to the coronavirus (COVID-19) pandemic. The paper has been expanded from the planned presentation.

Kang Yuan

bityuankang@126.com

$1 \quad$ BGRIMM Technology Group, Beijing 100160, China

2 BGRIMM Advanced Materials Science \& Technology Co., Ltd, Beijing 102206, China

3 Beijing Engineering Technology Research Center of Surface Strengthening and Repairing of Industry Parts, Beijing 102206, China substrate was studied, and a GOODMAN map for designing TCP-limited MCrAlY coatings can be provided.

Keywords core-shell · interdiffusion · MCrAlY . oxidation

\section{Introduction}

MCrAlY (M for Ni and/or Co) alloys have been widely used as overlay coatings to protect superalloy substrates against high-temperature oxidation and corrosion, or been used as bond coats in thermal barrier coating (TBC) system in aircraft engines and gas turbines (Ref 1). MCrAlY coatings can be manufactured by various coating techniques, for instance plasma spray (PS), high-velocity oxygen-fuel spray (HVOF), physical vapor deposition (PVD), arc ion plating processes, etc. (Ref 2-14).

At the high temperatures, not only the microstructure development in the coating is important, but also the coating-substrate interdiffusion play a key role on the properties and life of the material system (Ref 15-17). At high temperatures, both coating oxidation and coatingsubstrate interdiffusion can cause the $\mathrm{Al}$ depletion. In MCrAlY coatings, some typical microstructure were experimentally observed such as "core-shell" structures (Ref 9). In the past decades, commercial simulation softwares and databases have been greatly developed and the computer-aided modelling methods, especially using ThermoCalc and DICTRA, have shown promising results to simulate the behavior of the microstructure evolution and elemental diffusion in MCrAlY coatings or in MCrAlY-superalloy systems (Ref 18-21). By using simulation methods, the thermodynamic and kinetic mechanism 
of the microstructure development in the coating and superalloy can be investigated.

This paper will focus on the simulation of the elemental interdiffusion behavior in MCrAlY-superalloy systems. Firstly, a core-shell model was built to analyze the thermodynamic and kinetic mechanism of the formation of typical $\alpha$ (core) $-\gamma^{\prime}($ shell $)$ structure at lower temperature $\left(750{ }^{\circ} \mathrm{C}\right)$ and $\gamma$ (core) $-\beta$ (shell) structure at high temperature $\left(1100{ }^{\circ} \mathrm{C}\right)$ in the coating. A planner model was set up and used to simulate the elemental diffusion and microstructure evolution due to the coating-substrate interdiffusion. In this study, the interdiffusion simulation results were also analyzed and summarized with changing MCrAlY coating composition so that a GOODMAN map based on the existence or the formation of topologically closed packed (TCP) phases in the superalloy substrate can be drawn.

\section{Experimentals}

\section{Thermodynamic Calculation}

ThermoCalc software (ThermoCalc 2017a, bought from Thermo-Calc $A B$, Sweden) was used to calculate the thermodynamic equilibrium microstructure in a MCrAlY coating (i.e., Ni-22Cr-10Al, wt.\%, Y was ignored in the simulation) with database of TCNI8. The main phases related to the MCrAlY and the superalloy substrate were $\gamma$ (FCC_L12\#1), $\quad \gamma^{\prime}$ (FCC_L12\#2), $\alpha$ (BCC_B2\#1), $\beta$ (BCC_B2\#2), $\sigma$ (SIGMA), and $\mu$ (MU_Phase). The $\gamma$ phase was a disordered Ni-base phase in which other elements can be solid-soluted. The $\gamma^{\prime}$ and $\beta$ phases belonged to intermetallic compounds, owning $\mathrm{Ni}_{3}(\mathrm{Al}, \mathrm{Ta}, \mathrm{Ti})$ and $\mathrm{NiAl}$ nominal formulas, respectively.

\section{Diffusion Simulation in a Core-Shell Model}

Such structure was formed by typical coating process

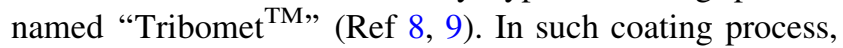
CrAlY powders were added in a slurry containing $\mathrm{Ni}$ or with Ni anode. The CrAlY core would be covered by $\mathrm{Ni}$ to form $\mathrm{CrAlY}$ core-Ni shell structure in as-deposited coating. As shown in Fig. 1(a), a core-shell model was built containing a $65 \mathrm{Cr}-33 \mathrm{Al}-2 \mathrm{Ni}$ core with diameter of $5 \mu \mathrm{m}$ and a $\mathrm{Ni}$ shell with thickness of $0.5 \mu \mathrm{m}$. A "rule-of-mixture" homogenization DICTRA modulus in the ThermoCalc software was used to calculate the elemental diffusion behavior in the core-shell model. The description of the "rule-of-mixture" modulus can be found in (Ref 4, 20, 22, 23). Two typical temperatures, i.e., 750 and $1100{ }^{\circ} \mathrm{C}$, were simulated for investigating the development of the two core-shell structures. In the diffusion simulations, TCNI8 and MOBNI4 databases were used. The phases of $\gamma$ and $\beta$ were included for the $1100{ }^{\circ} \mathrm{C}$ simulation while $\alpha, \gamma$ and $\gamma^{\prime}$ were included in the $750{ }^{\circ} \mathrm{C}$ case. Since the interdiffusion mainly occurred between the core and shell, the porosity and internal oxides in experimental samples was not much affect the reaction kinetics in the core-shell model. Of course the accuracy of the simulation results can be influenced by many factors such as the ignored effect of internal/external oxidation, the simplified core-shell size, the selection of homogenization model, the influence of the coating-substrate interdiffusion, database accuracy, etc. So the diffusion modelling only gave a semiquantitative prediction. But that was enough to understand the thermodynamic mechanism of the phase development in the coating in this paper.

\section{Diffusion Simulation in MCrAIY-Superalloy Planner Systems}

For the interdiffusion simulation in MCrAlY-superalloy systems, a planner model was built by using the "rule-ofmixture" homogenization DICTRA modulus. As shown in Fig. 1(b), the MCrAlY-superalloy diffusion couple contained a $100-\mu \mathrm{m}$-thick coating and a $1000-\mu \mathrm{m}$-thick substrate. The phases of $\gamma, \gamma^{\prime}, \alpha, \beta, \sigma$, and $\mu$ were included in the simulation. In this paper, temperatures from 750 to $1100{ }^{\circ} \mathrm{C}$ were simulated for $\mathrm{Ni} 22 \mathrm{Cr} 10 \mathrm{AlY}$ coating. The interdiffusion results of $1100{ }^{\circ} \mathrm{C}$ for $2,20,50$, and $100 \mathrm{~h}$ were used to analyze the composition and phase development with time. Temperature effect was studied by using data of 750,900 and $1000{ }^{\circ} \mathrm{C}$ for $500 \mathrm{~h}$. The superalloy used in the experiment was a Ni-based $\gamma / \gamma^{\prime}$ superalloy. The samples and the testing conditions are listed in Table 1; each condition had one sample. As mentioned above, many reasons can result in the inaccuracy of the simulations so that the diffusion modelling only gave a semiquantitative prediction. For more accurate simulating on the microstructure development, the surface oxidation effect of the MCrAlY coatings must be considered, which was temporarily ignored in this paper since the main aim of the interdiffusion simulation in this study was to understand the coating composition effect on the absence of TCP phases in the substrate. The porosity and internal oxides in experimental samples may affect the results when comparing with the simulation. The porosity and internal oxides' effect on the interdiffusion was not incorporated in the current work. Some MCrAlY coating compositions ( $Y$ was ignored in this simulation) designed for the planner simulations are shown in Table 2. The simulation condition to investigate the coating composition effect was at $1100{ }^{\circ} \mathrm{C}$ for $100 \mathrm{~h}$. 
Fig. 1 (a) A core-shell model, (b) a planner diffusion model with $100-\mu \mathrm{m}$-thick MCrAlY coating and $1000-\mu \mathrm{m}$-thick superalloy substrate
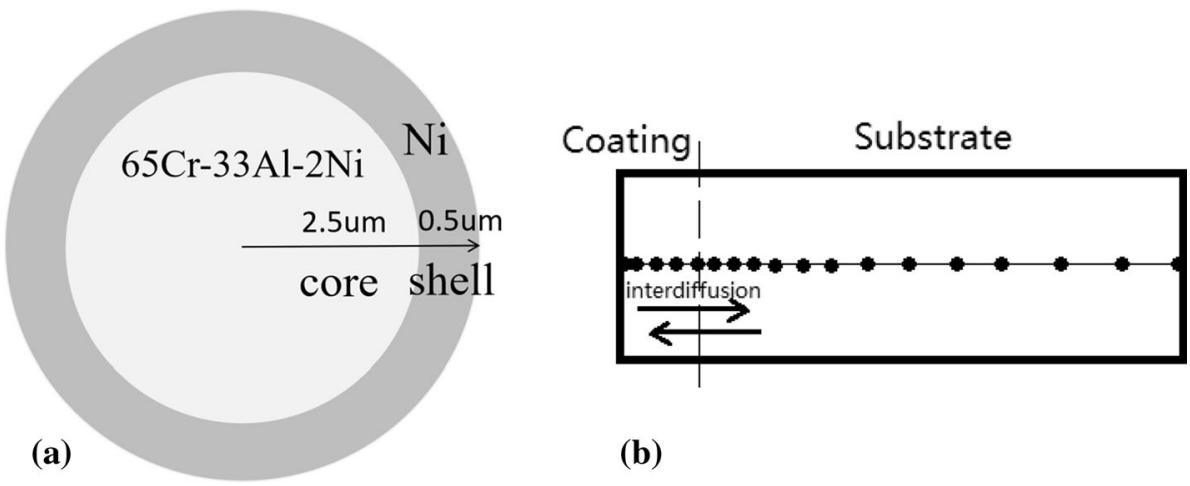

(b)

Table 1 The experimental testing conditions of samples

Oxidation temperature, ${ }^{\circ} \mathrm{C}$ Oxidation time, $\mathrm{h}$

1100

1100

1100

1100

900

750

Table 2 The MCrAlY coating composition in the modelling (wt.\%)

\begin{tabular}{llllll}
\hline Coatings & $\mathrm{Ni}$ & $\mathrm{Co}$ & $\mathrm{Cr}$ & $\mathrm{Al}$ & $\mathrm{Y}$ \\
\hline Coat $A$ & Bal. & 20 & 20 & 8 & $\ldots$ \\
Coat $B$ & Bal. & 25 & 25 & 8 & $\ldots$ \\
Coat $C$ & Bal. & 20 & 20 & 12 & $\ldots$ \\
Coat $D$ & Bal. & 30 & $\ldots$ & 10 & $\ldots$ \\
Coat $E$ & Bal. & $\ldots$ & 30 & 10 & $\ldots$ \\
Coat $F$ & $\ldots$ & Bal. & 30 & 10 & $\ldots$ \\
Coat $G$ & Bal. & $\ldots$ & 22 & 10 & $\ldots$ \\
\hline
\end{tabular}

\section{Results and Analyses}

\section{Equilibrium Microstructure Calculations of the Ni- 22Cr-10AIY Coating}

The equilibrium microstructure of the MCrAlY coating calculated is shown in Fig. 2. At 750 and $900{ }^{\circ} \mathrm{C}, \gamma^{\prime}-\mathrm{Ni}_{3} \mathrm{Al}$ (FCC structure) and $\alpha$-Cr (BCC structure) were formed. At 1000 and $1100{ }^{\circ} \mathrm{C}, \gamma$ - $\mathrm{NiCr}$ (FCC) and $\beta$ - $\mathrm{NiAl}(\mathrm{BCC})$ were formed. Around $1000{ }^{\circ} \mathrm{C}$, an obvious phase transformation point can be seen. As presenting in Table 3, the simulation results basically agreed with the experimental observation. The existence of some mismatches between the simulation and experiment was mainly due to the effect of the oxidation of the coating and the interdiffusion between the coating and the substrate, both of which can cause the coating composition changes. For example, $\beta$ phase would transfer to $\gamma^{\prime}$ or $\gamma$ phase when $\mathrm{Al}$ content in the coating decreased due to the oxidation and the interdiffusion effects.

\section{Core-Cell Modeling for the Ni-22Cr-10AIY Coating}

Figure 3 shows the composition and microstructure profiles in the core-shell structure for $750{ }^{\circ} \mathrm{C}$. At beginning, $\alpha$ phase was formed in the $\mathrm{Cr}$-Al-rich core while $\gamma$ phase formed in the $\mathrm{Ni}$ shell. With diffusion time, $\mathrm{Al}$ and $\mathrm{Cr}$ moved from the core to the shell while Ni migrated from the shell to the core. After the diffusion for $100 \mathrm{~h}, \mathrm{Cr}$ was still rich in the core promoting the formation of $\alpha$ phase while the inward diffusion Ni promoted the formation of $\gamma^{\prime}$ with combining some Al. Pure $\gamma^{\prime}$ was formed in the outer shell zone because of the outward diffusion of Al. The formation of $\gamma^{\prime}$ shell was due to the outward diffusion of $\mathrm{Al}$ which showed an "uphill" diffusion behavior. The composition profiles did not changed much for longer time and the $\alpha($ core $) / \gamma^{\prime}$ (shell) microstructure was kept up to $5000 \mathrm{~h}$ (Fig. 3b), which agree with the experimental observation.

Figure 4(a) presents the development of $\mathrm{Al}$ profiles with time at $750{ }^{\circ} \mathrm{C}$. As the result shows, at the beginning $\mathrm{Al}$ in the core diffused towards to the shell side. After $10 \mathrm{~h}$, the $\mathrm{Al}$ concentration in the shell became higher than that in the core, i.e., that "uphill" diffusion occurred. The $\mathrm{Al}$ profile became almost not changed in 10-5000 h. As shown in Fig. 5(b), the activity of $\mathrm{Al}$ through the whole core-shell structure had become the same from $10 \mathrm{~h}$ after that the $\alpha($ core $) / \gamma^{\prime}$ (shell) structure can be stably formed. Because the activity of the elements in the core and shell became the same, there would be no further diffusion occurring.

In experiments, the core-shell structure contained typical $\gamma / \gamma^{\prime} / \beta$ microstructure in the coatings at short oxidation time. The $\beta$ phases were distributed around the deposited particles, which was a diffusion-induced phenomenon. At longer times, the $\beta$ phase would be depleted due to 
Fig. 2 Thermodynamic calculation on phase fractions of the MCrAlY coating (Ni-22Cr10Al)

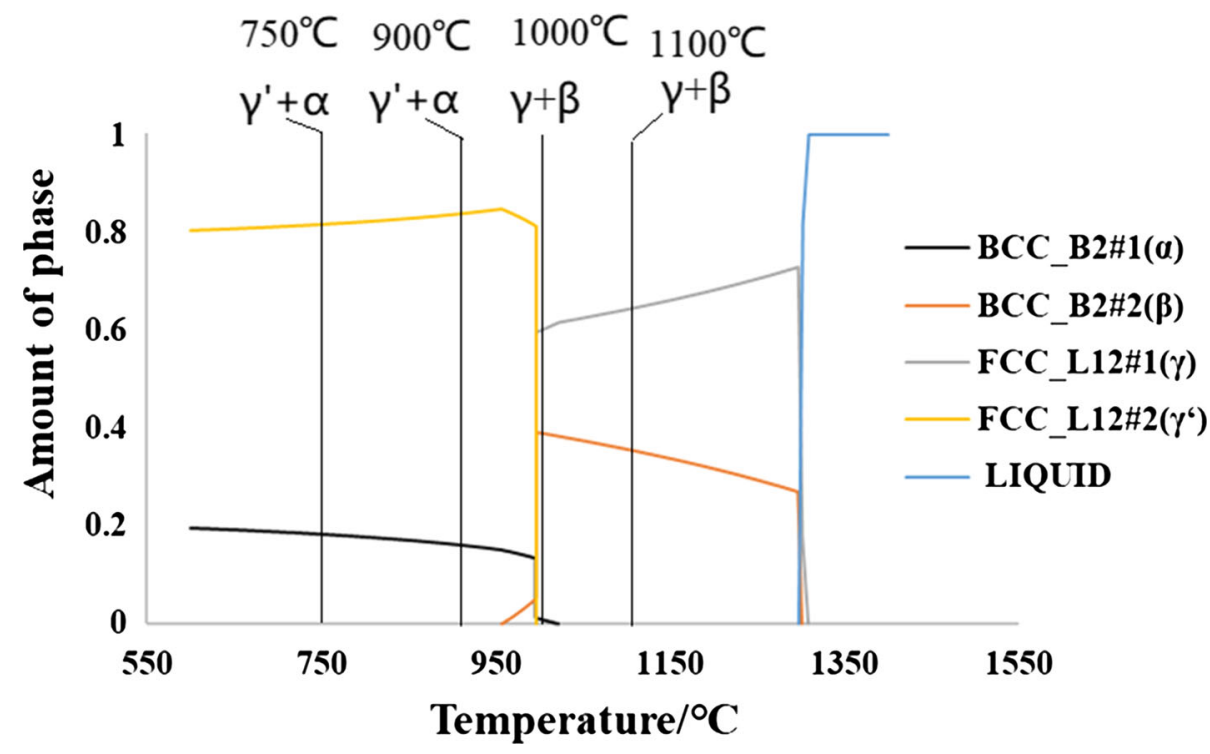

Table 3 Phases in $\mathrm{Ni}-22 \mathrm{Cr}$ $10 \mathrm{AlY}$ coating

\begin{tabular}{lllll}
\hline & \multicolumn{1}{c}{$750{ }^{\circ} \mathrm{C}$} & \multicolumn{1}{c}{$900{ }^{\circ} \mathrm{C}$} & $1000{ }^{\circ} \mathrm{C}$ & \multicolumn{1}{c}{$1100{ }^{\circ} \mathrm{C}$} \\
\hline Sim. (equilibrium) & $\gamma^{\prime}+\alpha$ & $\gamma^{\prime}+\alpha$ & $\gamma+\beta$ & $\gamma+\beta$ \\
Exp. & $\gamma^{\prime}+\alpha(500 \mathrm{~h})$ & $\gamma+\gamma^{\prime}+\alpha(500 \mathrm{~h})$ & $\gamma(500 \mathrm{~h})$ & $\gamma+\gamma^{\prime}+\beta(2 \mathrm{~h})$ \\
\hline
\end{tabular}

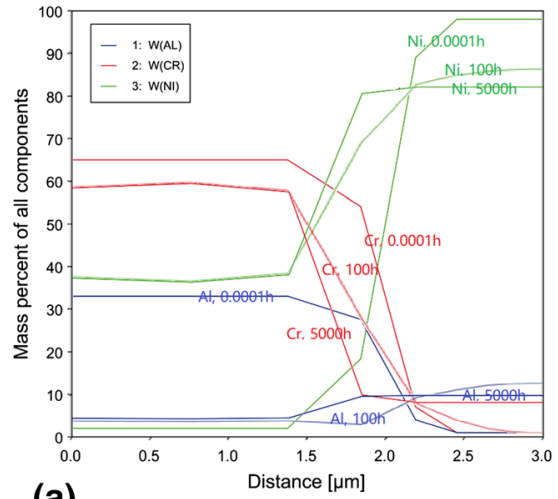

(a)

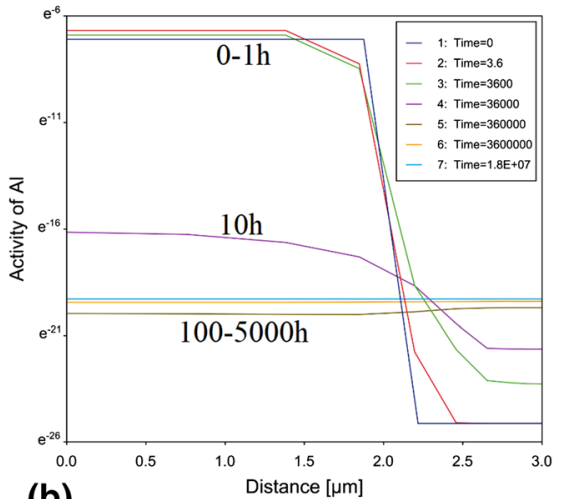

(b)

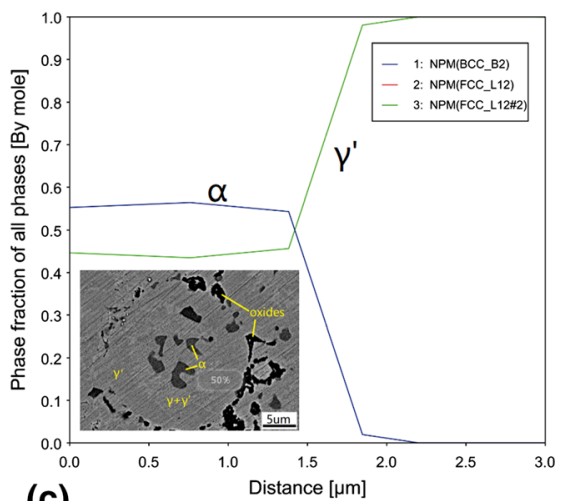

(c)

Fig. 3 Core-shell modelling results for $750{ }^{\circ} \mathrm{C}$. (a) composition profiles $(0-5000 \mathrm{~h})$, (b) development of $\mathrm{Al}$ activity $(0-5000 \mathrm{~h})$, (c) phase profiles $(5000 \mathrm{~h})$

oxidation and interdiffusion between the coating and substrate, and the coating would loss such core-shell structure in experiments, because the oxidation of the coating and the coating-substrate interdiffusion had highly consumed the $\mathrm{Al}$ content which broke out the original equilibrium balance in the core-shell structure and caused the $\beta$ phase degradation in the coating. Figure 5(a) and (b) give the composition and activity profiles of $\mathrm{Al}$ at $1100{ }^{\circ} \mathrm{C}$. As the result shows, the Al profile became stable after a few seconds. The result demonstrated that the elemental activity between the core and the shell had become the same from the very early time. Figure 5 (c) gives the distribution of the elements between the core and shell. Al was richer in the shell side and $\mathrm{Cr}$ was richer in the core side. That can explain the formation of the $\gamma$ (core) $-\beta$ (shell) structure shown in Fig. 5(d).

\section{Interdiffusion Simulation in the Ni-22Cr-10AIY/ Superalloy System}

The interdiffusion results of some typical elements at $1100{ }^{\circ} \mathrm{C}$ are given in Fig. 6; $\mathrm{Al}$ and $\mathrm{Cr}$ were coating elements while $\mathrm{Co}$ and $\mathrm{W}$ were superalloy elements. In the simulation results, distance from -100 to $0 \mu \mathrm{m}$ was coating part, while 0 to $1000 \mu \mathrm{m}$ was substrate. At $1100{ }^{\circ} \mathrm{C}$, even in a short time $(2 \mathrm{~h})$ obvious diffusion took 

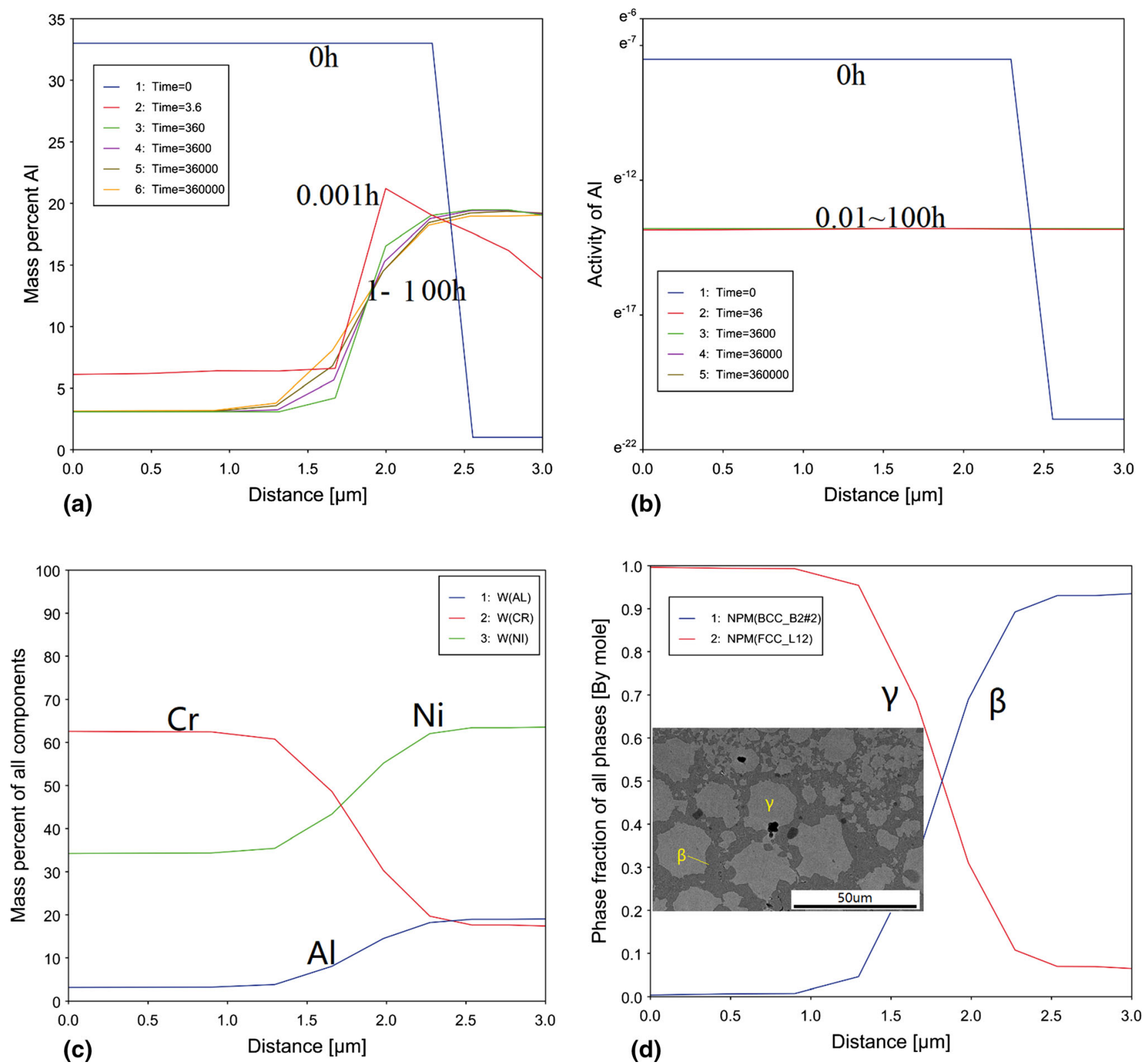

Fig. 4 Core-shell modelling results for $1100{ }^{\circ} \mathrm{C}$. (a) development of $\mathrm{Al}$ composition $(0-100 \mathrm{~h})$, (b) development of $\mathrm{Al}$ activity (0-100 h), (c) composition profiles at $100 \mathrm{~h},(\mathrm{~d})$ phase profiles at $100 \mathrm{~h}$

place. Coating elements such as $\mathrm{Al}$ and $\mathrm{Cr}$ diffused into substrate while substrate elements such as Co and W diffuse into coating side. After $100 \mathrm{~h}$, the coating composition almost became the same as the substrate because of the homogenization effect of interdiffusion. Phases in the coating and substrate were also developed. At $2 \mathrm{~h}$, the coating's microstructure changed to $\gamma+\beta+\alpha$. Near the coating-substrate interface, $\beta$ was depleted due to the lose of Al. After $20 \mathrm{~h}$, the coating had changed to $\gamma+\gamma^{\prime}$ as the main phases. Up to $100 \mathrm{~h}$, the coating had almost the same fraction of $\gamma / \gamma^{\prime}$ as the substrate. The simulation did not predict the formation of TCP phases in the substrate for all time. In the experiment, very limited TCP phases were formed with volume content less than $3 \%$.

Figure 7 and 8 show the temperature effect on the elemental diffusion and microstructure developing behavior (750-1000 ${ }^{\circ} \mathrm{C}$ ). All data was for time of $500 \mathrm{~h}$. The diffusion of elements at 750 and $900{ }^{\circ} \mathrm{C}$ was very slow, and the coating kept the as-received $\gamma^{\prime}+\alpha$ microstructure. In the substrate, the formation of $\sigma$ phase was near the interface was predicted but with a very small amount. The formation of $\sigma$ phase can be used to characterize the depth of diffusion zones in the substrate. About 25 and $50 \mu \mathrm{m}$ diffusion zones were formed at 750 and $900{ }^{\circ} \mathrm{C}$, 

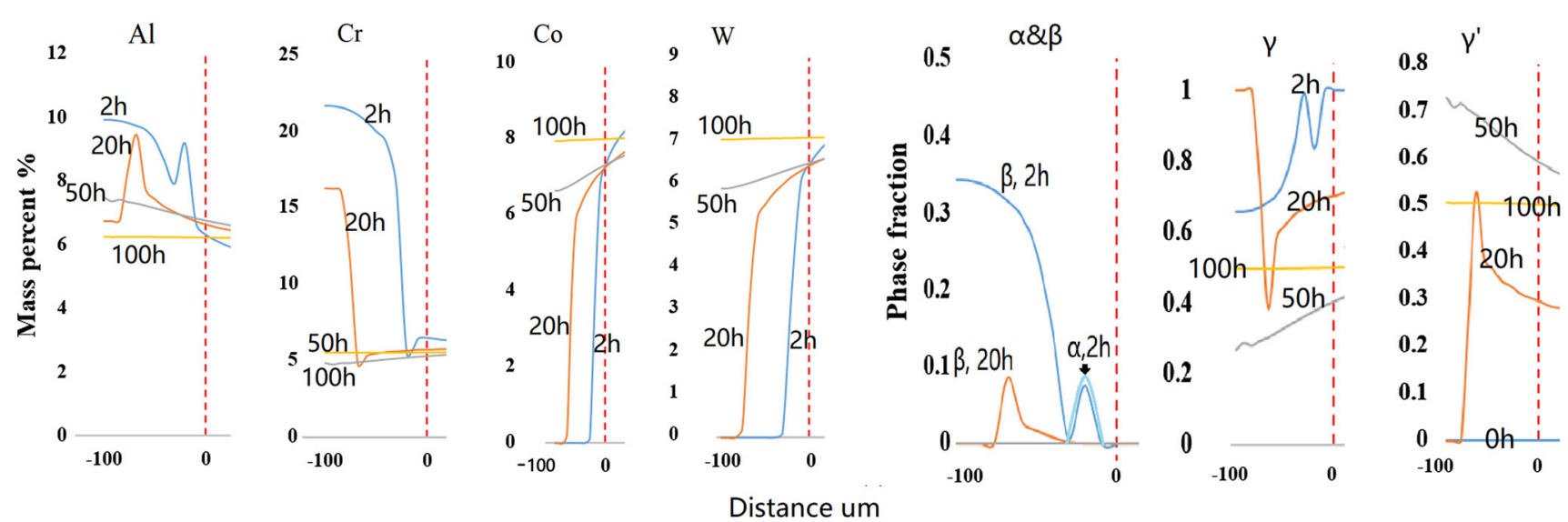

Fig. 5 Composition and phase profiles in Ni22Cr10Al-substrate system after interdiffusion simulation at $1100{ }^{\circ} \mathrm{C}$

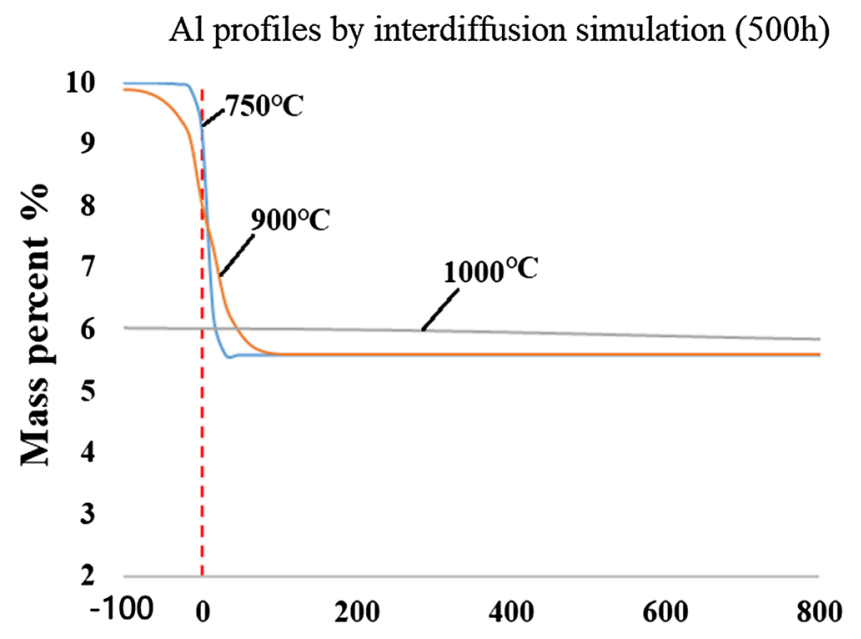

(a)

Distance/ $\mu \mathrm{m}$

Co profiles by interdiffusion simulation $(500 \mathrm{~h})$

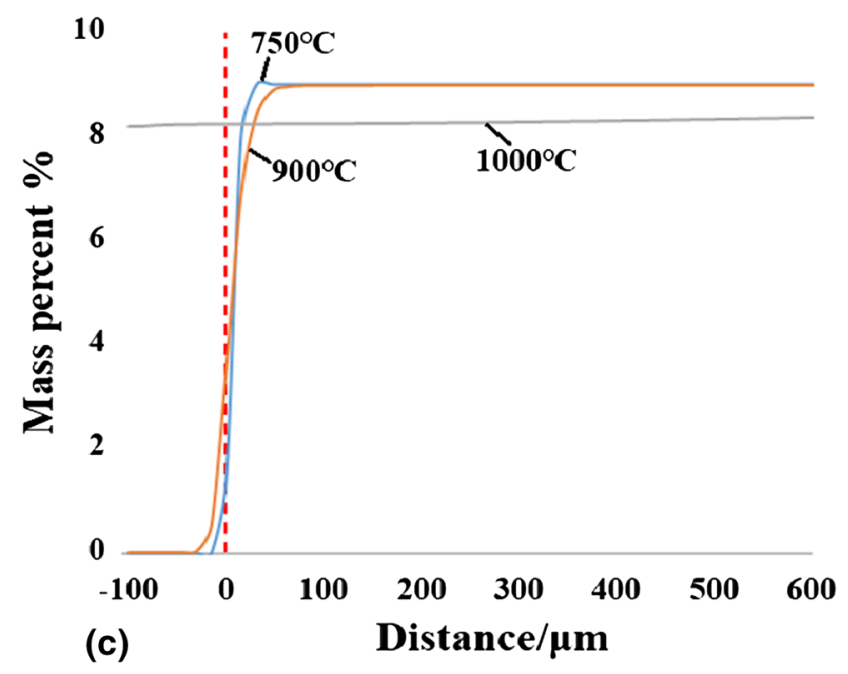

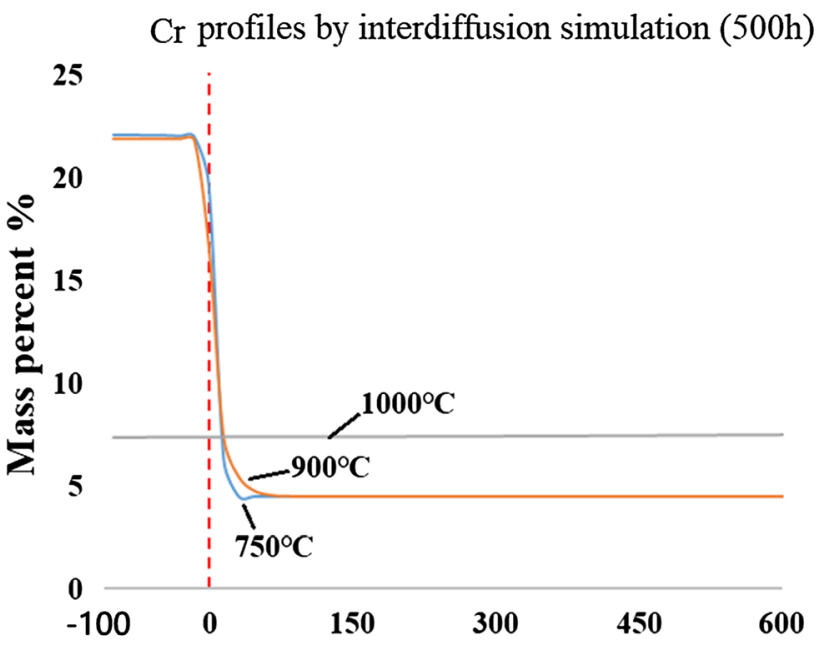

(b)

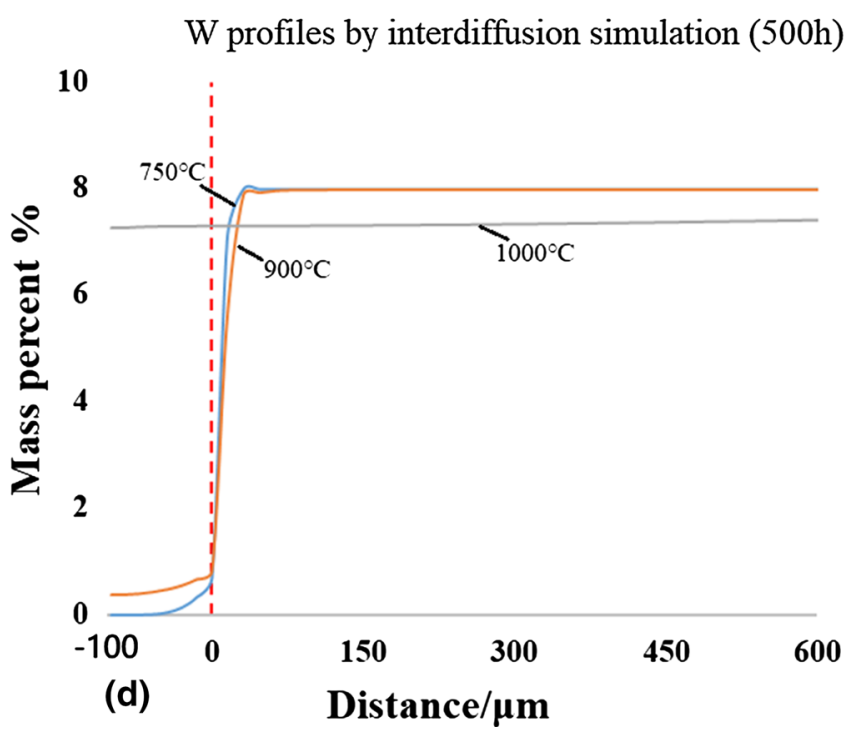

Fig. 6 Composition profiles in MCrAlY-substrate system after interdiffusion simulation at different temperatures for $500 \mathrm{~h}$. (a) Al, (b) Cr, (c) $\mathrm{Co},(\mathrm{d}) \mathrm{W}$ 

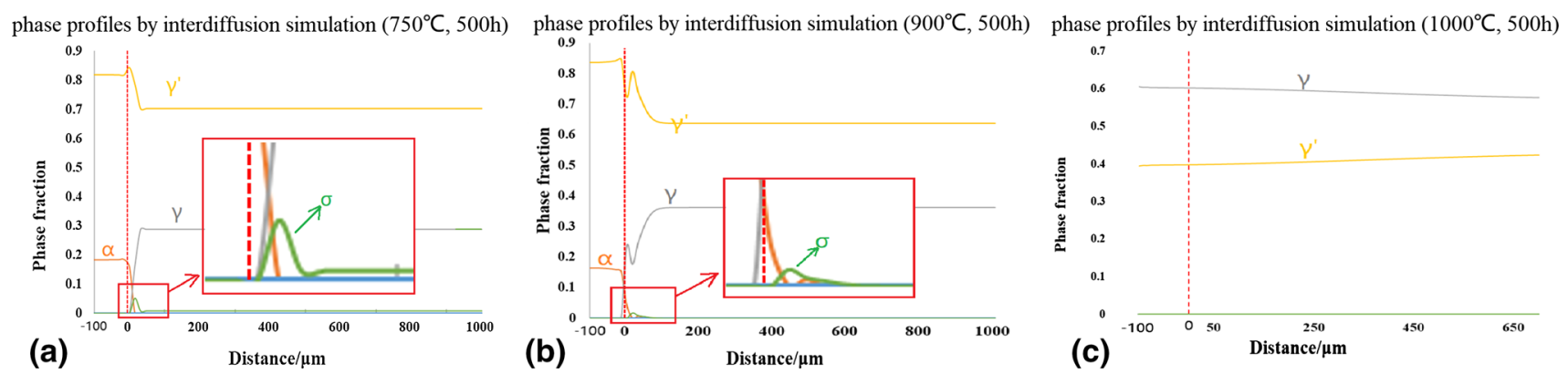

Fig. 7 Phase profiles in MCrAlY-substrate system after interdiffusion simulation at different temperatures for $500 \mathrm{~h}$. (a) $750{ }^{\circ} \mathrm{C}$, (b) $900{ }^{\circ} \mathrm{C}$, (c) $1000{ }^{\circ} \mathrm{C}$
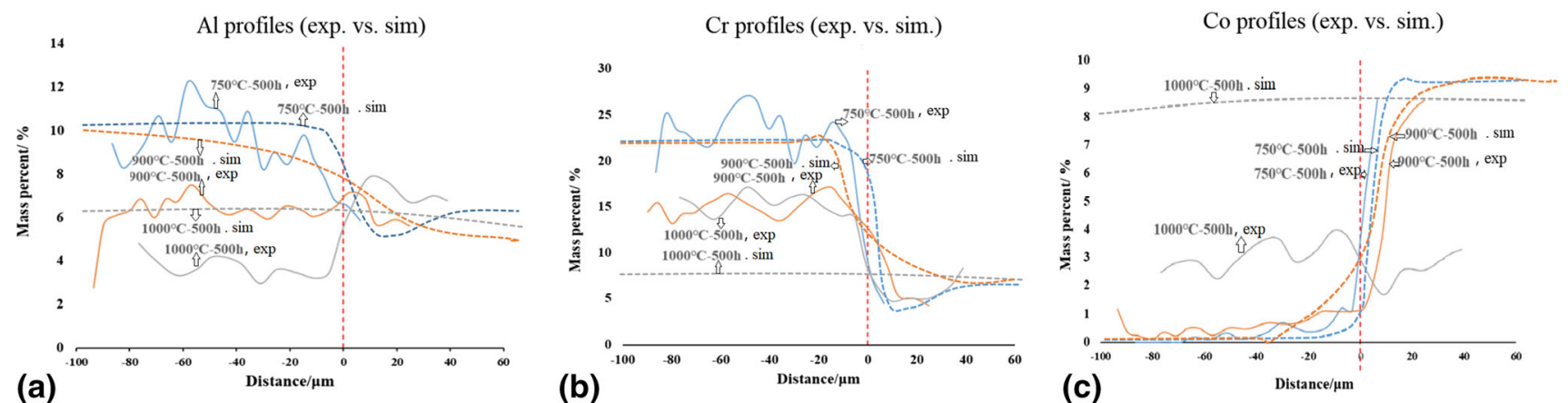

Fig. 8 A comparison of experimental (exp) and simulation (sim) data of composition profiles. Solid lines for exp results and dash lines for sim results. (a) $\mathrm{Al}$, (b) $\mathrm{Cr}$, (c) $\mathrm{Co}$

respectively. At $1000{ }^{\circ} \mathrm{C}$, a total homogenization of all elements and phases was predicted by the simulation.

Figure 9 compares the composition profiles obtained from experiment and simulation. The simulation data for $750{ }^{\circ} \mathrm{C}$ semiquantitatively agrees with the experimental data as the oxidation of the coating at such low temperature was not heavy. For 900 and $1000{ }^{\circ} \mathrm{C}$, the oxidation (externally and internally) caused highly $\mathrm{Al}$ depletion in experiments. Therefore, the simulated $\mathrm{Al}$ concentration in the coating was higher than that from experimental data. The mismatch between the simulation and the experiment is shown in Table 4 by analyzing the coating average composition. Such mismatch was caused by several reasons: (1) imperfect simulation database and the homogenization modulus selection; (2) no consideration of oxidation in simulation. However, the diffusion model indeed can predict the basic trend of elemental diffusion and the behavior of microstructure development, especially the development of diffusion zones near the coating-substrate interface and the formation of TCP phases in substrate. Therefore, the MCrAlY-superalloy planner model can be used to investigate the coating composition on the microstructure development of the superalloy substrate.

\section{Interdiffusion Simulation in Different MCrAIY- Superalloy Systems}

To investigate the effect of coating composition on the interdiffusion behavior especially the formation of TCP phases in the superalloy substrate, different MCrAlY-superalloy planner systems were simulated (see Table 1). Figure 10 gives an example of how the elements diffused and phase developed in the materials (taking Coat $A$ as an example, $\mathrm{Ni}$ as the balance element in the figure). After an interdiffusion at $1100{ }^{\circ} \mathrm{C}$ for $100 \mathrm{~h}$, coating elements $\mathrm{Co}$, $\mathrm{Cr}$ and $\mathrm{Al}$ diffused inwards to the substrate. Due to the lost of $\mathrm{Al}$ in the coating, $\beta$ phase has been highly depleted. In the substrate, a $\gamma^{\prime}$ depletion zone was formed just beneath the coating-substrate interface, following which a $\gamma^{\prime}$-rich zone (at $\sim$ distance $=150 \mu \mathrm{m})$ was produced. In this $\gamma^{\prime}$ rich zone, TCP phases ( $\mu$ and $\sigma$ ) were formed. The inward diffusion of $\mathrm{Co}$ and $\mathrm{Cr}$ caused the depletion of $\gamma^{\prime}$ phase in the substrate since their concentration in this zone changed a lot comparing to the original composition. The deeper formed $\gamma^{\prime}$-rich zone contained higher amount of $\mathrm{Al}$ due to its fast inward diffusion. As the inward diffusion of $\mathrm{Al}$ produced higher fraction of $\gamma^{\prime}$, the amount of $\gamma$ phase decreased and simultaneously some heavy elements such as W, Mo and Re oversaturated to form TCP precipitates. 

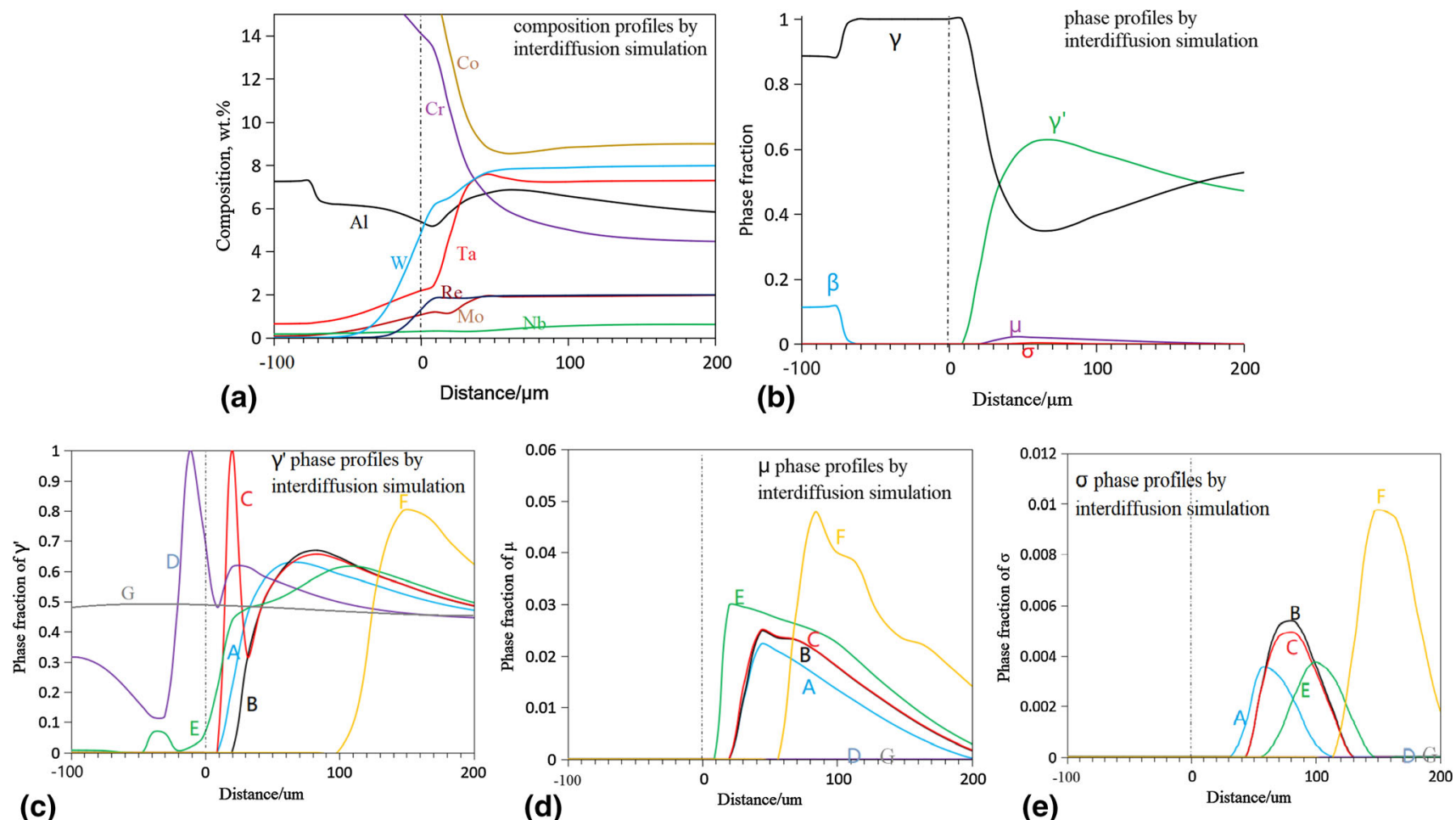

Fig. 9 Interdiffusion modelling results in coating-substrate systems at $1100{ }^{\circ} \mathrm{C}$ for $100 \mathrm{~h}$ : (a) and (b) for elemental composition and phase fraction curves (Coat A-substrate), (c)-(e) for the influence of the coating composition on the formation of $\gamma^{\prime}, \mu$ and $\sigma$ phases

Table 4 A comparison of experimental (exp) and simulation (sim) data of coating composition (average composition)

\begin{tabular}{|c|c|c|c|c|c|c|}
\hline & \multicolumn{2}{|c|}{$\mathrm{Al}$} & \multicolumn{2}{|c|}{$\mathrm{Cr}$} & \multicolumn{2}{|c|}{ Co } \\
\hline & Exp. & Sim. & Exp. & Sim. & Exp. & Sim. \\
\hline As-rec. & 9.9 & 10 & 25.6 & 22 & 0.05 & 0 \\
\hline $750{ }^{\circ} \mathrm{C}, 500 \mathrm{~h}$ & 10.1 & 9.9 & 25.2 & 21.7 & 0.16 & 0.18 \\
\hline $900^{\circ} \mathrm{C}, 500 \mathrm{~h}$ & 6.5 & 9.5 & 15.4 & 21.2 & 0.43 & 0.52 \\
\hline $1000{ }^{\circ} \mathrm{C}, 500 \mathrm{~h}$ & 4.1 & 6 & 15.9 & 5.6 & 3 & 8.2 \\
\hline $1100^{\circ} \mathrm{C}, 2 \mathrm{~h}$ & 10.4 & 9.1 & 20.6 & 17.8 & 0.66 & 0.99 \\
\hline $1100^{\circ} \mathrm{C}, 20 \mathrm{~h}$ & 7.9 & 7.4 & 19.3 & 9 & 1.5 & 3.9 \\
\hline $1100^{\circ} \mathrm{C}, 50 \mathrm{~h}$ & 6.3 & 7.2 & 18.8 & 5 & 2 & 6.9 \\
\hline $1100{ }^{\circ} \mathrm{C}, 100 \mathrm{~h}$ & 7.2 & 6.1 & 18.7 & 5.5 & 2.5 & 8 \\
\hline
\end{tabular}

The coating composition effect on the $\gamma^{\prime}$ depletion and TCP phase formation is analyzed in Fig. 11. Figure 11(a) shows that higher Co and $\mathrm{Cr}$ amount (comparing Coat $A$ and $B$ ) gave larger depth of $\gamma^{\prime}$ depletion in the substrate. Higher Al content of the coatings (comparing Coat $A$ and $C$ ) caused the high amount of $\gamma^{\prime}$ phase in the $\gamma^{\prime}$ rich zone but did not change the depth of the diffuse zone. Obviously, a Ni-based coating (Coat $D$ ) had better ability to hold the $\gamma / \gamma^{\prime}$ microstructure in substrate than a Co based one (Coat $F)$. Increasing coatings' $\mathrm{Cr}$ or $\mathrm{Al}$ amount can increase the amount and depth of the TCP phases according to the results in Fig. 11(b) and (c). Coat $D$ and $G$ did not promote the formation of TCP phases in the substrate probably due to their lower amount of $\mathrm{Co}$ and $\mathrm{Cr}$. In the experiment, very limited TCP phases were formed with volume fraction less than 0.01 in Coat $G$-substrate system (Fig. 11b). As shown in the figure, the TCP phases were formed in the SRZ; no TCP was found in IDZ. The TCP phases were rich $\mathrm{W}$ and Mo and had "needle"-like shape which was formed due to the inward diffusion of $\mathrm{Al}$ and $\mathrm{Cr}$ from the coating. Even though there was some mismatch between the experimental and simulation results on the formation of TCP phases in Coat $G$-substrate system, Coat $G$ can still be regarded as a coating to cause no significant TCP phases for the substrate. Being encouraged by that, the interdiffusion simulation can be extended for predicting whether a coating can or can not to promote the significant formation of TCP phases in the superalloy.

Figure 12 gives a GOODMAN map to show the effect of the coating composition on the formation of TCP phases due to the coating-substrate interdiffusion which may help engineers to design a MCrAlY coating without forming TCP phases in the superalloy. In the figure, " $\bigcirc$ " was for no $\mu / \sigma$ forming in the substrate (interdiffusion zone), " $\Delta$ " was for only small amount (less than $10 \%$ ) of $\sigma$ forming, and " $\mathrm{x}$ " was for large amount of $\mu / \sigma$ forming. The GOODMAN map was drawn based on the calculation results for condition of $1100{ }^{\circ} \mathrm{C}$ for $100 \mathrm{~h}$. For such high temperature the elements 

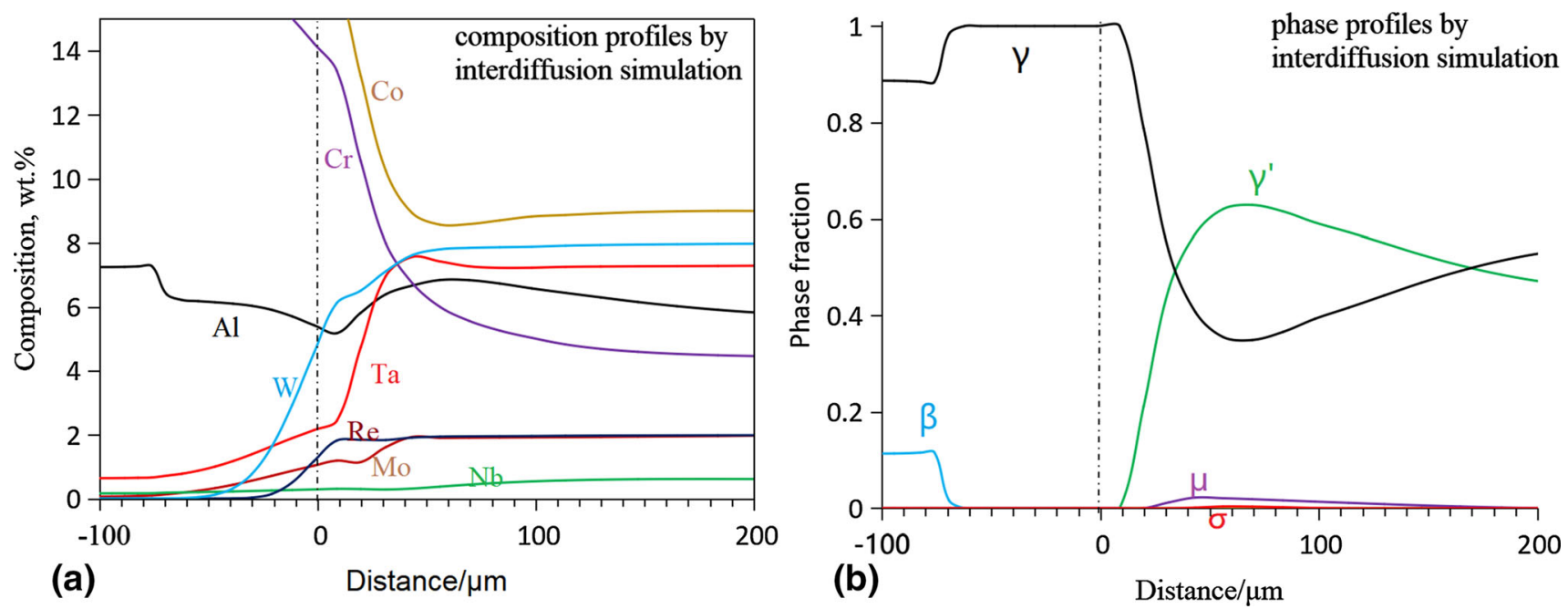

Fig. 10 Interdiffusion modelling results in Coat A-substrate system at $1100{ }^{\circ} \mathrm{C}$ for $100 \mathrm{~h}$. (a) for elemental composition curves, (b) for phase fraction curve

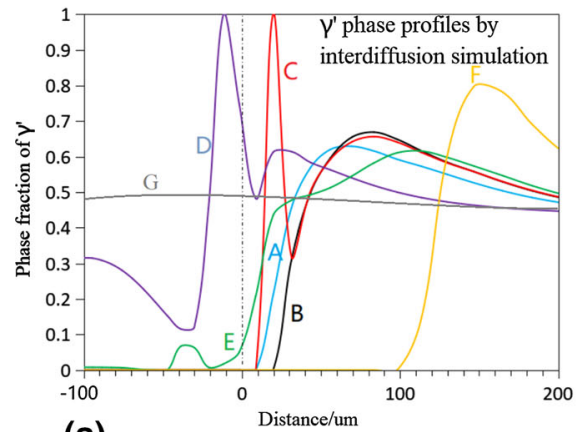

(a)

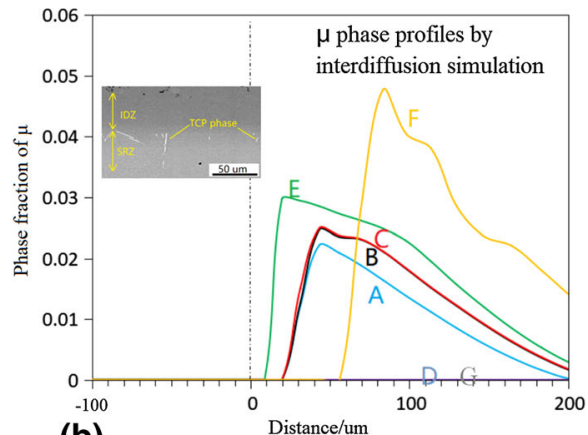

(b)

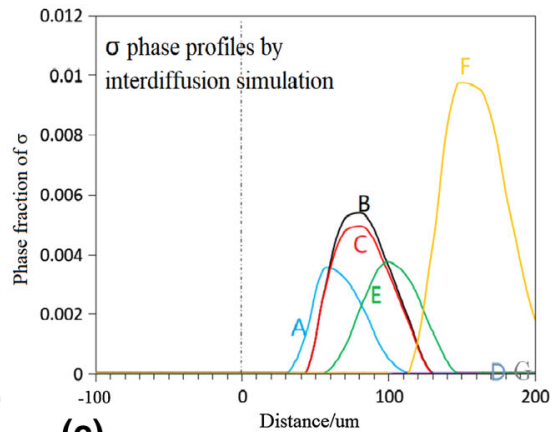

(c)
Fig. 11 Simulation results of the influence of the coating composition on the formation of (a) $\gamma^{\prime}$, (b) $\mu$ and (c) $\sigma$ phases in coating $(-100 \sim 0 \mu \mathrm{m})$ - substrate $(0 \sim 200 \mu \mathrm{m})$ systems at $1100{ }^{\circ} \mathrm{C}$ for

had highly interdiffused between the coating and the substrate. In the experiments, there was no obvious TCP phases formed in the NiCrAlY-superalloy system which agreed with the results shown in the GOODMAN map. Such GOODMAN map was only applicable for coating made by processes like "Tribomet ${ }^{\mathrm{TM}}$ " $(\operatorname{Ref} 8,9)$ in which no sand blasting (stresses) and thermal or impacting effect on the substrate during the coating process. The coating composition at green " $\bigcirc$ " did not promote TCP phase formation in the substrate. With the coatings at " $\Delta$ " position, only small amount of $\sigma$ phase (less than 2\%) was formed in the substrate and no $\mu$ phase was formed. Obvious $\mu$ and $\sigma$ phases were formed when the coating composition was at " $\mathrm{x}$ " positions. Based on the simulation results, a MCrAlY coating with the total amount of $\mathrm{Co}+\mathrm{Cr}<25 \%$ was safe for the superalloy in which no obvious TCP phases can form due to the coatingsubstrate interdiffusion effect. Such GOODMAN map is more suitable for high temperatures; for lower temperatures, more calculations should be done.
100 h. Coat D and G showed no TCP phases. In (b), a SEM image is given showing the very limited formation of TCP phases in substrate with coating Coat $\mathrm{G}$

\section{Conclusions}

In this paper, two diffusion models were built to simulate the diffusion behavior of elements in the coating or in the coating-substrate system. The diffusion results basically agreed with the experimental observations.

(1) A (Cr-Al)core-(Ni)shell model was set up to investigate the thermodynamic and kinetic behavior of the localized microstructure. Al diffused to the Ni-rich shell to form pure $\gamma^{\prime}$-based shell at $750{ }^{\circ} \mathrm{C}$ while to form pure $\beta$-based shell at $1100{ }^{\circ} \mathrm{C}$. Ni diffused into the Cr-rich core to form $\alpha+\gamma^{\prime}$ core at $750{ }^{\circ} \mathrm{C}$ while to form $\gamma$-based core at $1100{ }^{\circ} \mathrm{C}$. The driving force to form those special core-shell microstructure was the elemental activities which usually can reach a balance between the core and the shell after a very short time.

(2) A coating-substrate planner model was used to simulate the interdiffusion of elements between the 


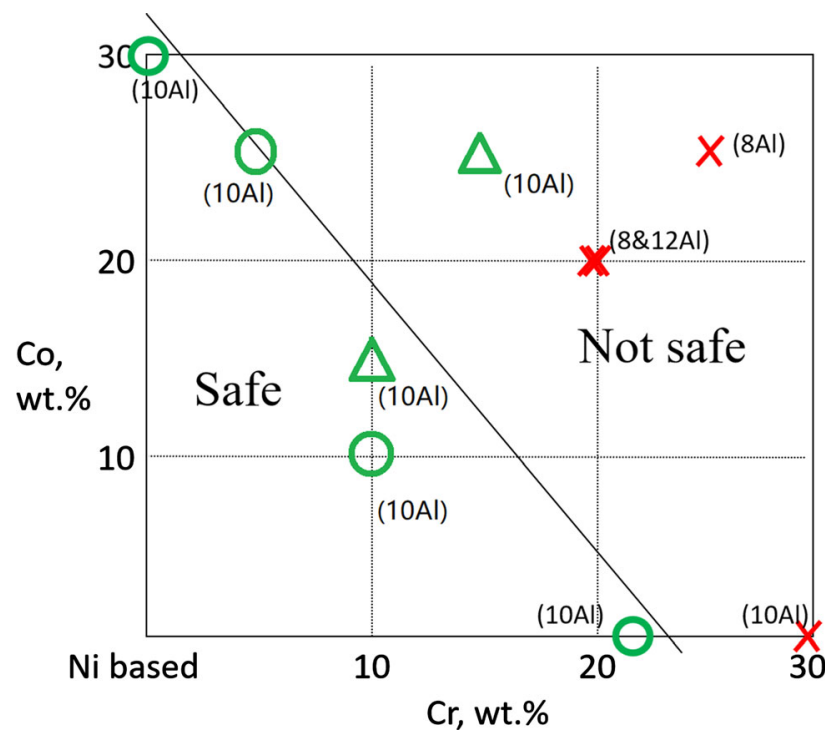

Fig. 12 A GOODMAN map for NiCoCrAlY coating design by considering the formation of TCP phases in the superalloy substrate (Ref 15) (" $\bigcirc$ " for no $\mu / \sigma$ forming, " $\Delta$ " for only small amount of $\sigma$ forming, "x" for large amount of $\mu / \sigma$ forming). Safe zone does not have obvious TCP phases forming in substrate, while not safe zone has

MCrAlY coating and the superalloy substrate. The simulation results in the Ni22Cr10AlY-superalloy system semiquantitatively agreed with the experimental observation if not counting in the oxidation effects in short diffusion time.

(3) By applying the planner diffusion model, the effect of the MCrAlY coatings on the formation of TCP phases in the substrate was studied. Based on the current simulation results of whether a high amount of TCP phases were formed in the substrate, a GOODMAN map can be drawn. The GOODMAN map showed that a MCrAlY with $\mathrm{Co}+\mathrm{Cr}$ amount less than $25 \%$ was safe with limited amount of TCP phases to form in the substrate.

Acknowledgments Great acknowledgments are extended to the final support by National Science and Technology Major Project (2017VII-0012-0109), Beijing Science Technology Plans (Grand No. KZ201910009010) and the BGRIMM company projects (Grant Nos. 02-1930, 02-2003-1, 04-1926).

\section{References}

1. W. Brandl, H.J. Grabke, D. Toma, and J. Krüger, The Oxidation Behaviour of Sprayed MCrAY Coatings, Surf. Coat. Technol., 1996, 86, p 41-47

2. B.K. Pant, V. Arya, and B.S. Mann, Development of Low-Oxide MCrAlY Coatings for Gas Turbine Applications, J. Therm. Spray Technol., 2007, 16(2), p 275-280
3. G.W. Goward, Progress in Coatings for Gas Turbine Airfoils, Surf. Coat. Technol., 1998, 108-109, p 73-79

4. K. Yuan, R.L. Peng, X.H. Li, S. Johansson, and Y.D. Wang, Some Aspects of Elemental Behaviour in HVOF MCrAlY Coatings in High-Temperature Oxidation, Surf. Coat. Technol., 2014, 261, p 86-101

5. Y.H. Sohn, J.H. Kim, E.H. Jordan, and M. Gell, Thermal Cycling of EB-PVD/MCrAlY Thermal Barrier Coatings: I. MICROSTRUCTURAL DEVELOPMENT and Spallation Mechanisms, Surf. Coat. Technol., 2001, 146-147, p 70-78

6. S.M. Jiang, X. Peng, Z.B. Bao, S.C. Liu, Q.M. Wang, J. Gong, and C. Sun, Preparation and Hot Corrosion Behaviour of a MCrAlY/AlSiY Composite Coating, Corros. Sci., 2008, 50, p 3213-3220

7. A.V. Put, M.C. Lafont, D. Oquab, A. Raffaitin, and D. Monceau, Effect of Modification by Pt and Manufacturing Processes on the Microstructure of Two NiCoCrAlYTa Bond Coatings Intended for Thermal Barrier System Applications, Surf. Coat. Technol., 2010, 205(3), p 717-727

8. L.Z. Zhang, B.L. Bates, and Y. Zhang, Effect of Post-deposition Heat Treatment on Electrodeposited NiCoCrAlY Coatings, Energy Mater., 2016, 33, p 136-141

9. R. Goti, M. Bétaille-Francoual, E. Hourcastagné, B. Viguier, and F. Crabos, Isothermal Oxidation Behaviour of NiCoCrAlYTa Coatings Produced by HVOF Spraying and Tribomet ${ }^{\mathrm{TM}}$ Process, Oxid. Met., 2014, 81(1), p 105-113

10. D. Texier, D. Monceau, F. Crabos, and F. Andrieu, Tensile Properties of a Non-line-of-sight Processed $\beta-\gamma-\gamma^{\prime}$ MCrAlY Coating at high Temperature, Surf. Coat. Technol., 2017, 326, p 28-36

11. T. Taylor and J. Foster, Thermal expansion of Tribomet MCrAlY Coatings, Surf. Coat. Technol., 2006, 201, p 3819-3823

12. Y. Zhang, Electrodeposited MCrAlY Coatings for Gas Turbine Engine Applications, JOM, 2015, 67(11), p 1-9

13. B.L. Bates, J.C. Witman, and Y. Zhang, Electrolytic Co-deposition of Ni-CrAlY Composite Coatings Using Different Deposition Configurations, Mater. Manuf. Process., 2016, 31, p 12321237

14. B.L. Bates, L.Z. Zhang, and Y. Zhang, Electrodeposition of Ni Matrix Composite Coatings with Embedded CrAlY Particles, Surf. Eng., 2015, 31(3), p 202-208

15. H.E. Evans and M.P. Taylor, Diffusion Cells and Chemical Failure of MCrAlY Bond Coats in Thermal-Barrier Coating Systems, Oxid. Met., 2001, 55, p 17-34

16. P. Zhang, R.L. Peng, and X.H. Li, Failure Mechanism of MCrAlY Coating at the Coating-Substrate Interface Under Type I, Hot Corrosion, Mater. Corr., 2019, 70(9), p 1593-1600

17. J. Toscano, D. Naumenko, A. Gil, L. Singheiser, and W.J. Quadakkers, Parameters Affecting TGO Growth Rate and the Lifetime of TBC Systems with MCrAlY-Bondcoats, Mater. Corr., 2008, 59, p 501-507

18. R. Pillai, W.G. Sloof, A. Chyrkin, L. Singheiser, and W.J. Quadakkers, A New Computational Approach for Modelling the Microstructural Evolution and Residual Lifetime Assessment of MCrAlY Coatings, Mater. High Temp., 2015, 32, p 57-67

19. S. Salam, P.Y. Hou, Y.D. Zhang, H.F. Wang, C. Zhang, and Z.G. Yang, Compositional Effects on the High-Temperature Oxidation Lifetime of MCrAlY Type Coating Alloys, Corros. Sci., 2015, 95, p 143-151

20. K. Yuan, R. Eriksson, R.L. Peng, X.L. Li, S. Johansson, and Y.D. Wang, Modeling of Microstructural Evolution and Lifetime Prediction of MCrAlY Coatings on Nickel Based Superalloys During High Temperature Oxidation, Surf. Coat. Technol., 2013, 232, p 204-215 
21. H. Chen, G.A. Jackson, K.T. Voisey, and D.G. Mccartney, Modelling and Experimental Study on $\beta$-Phase Depletion Behaviour of HVOF Sprayed Free-Standing CoNiCrA1Y Coatings During Oxidation, Surf. Coat. Technol., 2016, 291, p 34-42

22. K. Yuan, R. Eriksson, R.L. Peng, X.H. Li, S. Johansson, and Y.D. Wang, MCrAlY Coating Design Based on Oxidation-Diffusion Modelling. Part I: Microstructural Evolution, Surf. Coat. Technol., 2014, 254, p 79-96
23. R. Eriksson, K. Yuan, X.H. Li, and R.L. Peng, MCrAlY Coating Design Based on Oxidation-Diffusion Modelling. Part II: Lifing Aspects, Surf. Coat. Technol., 2014, 253, p 27-37

Publisher's Note Springer Nature remains neutral with regard to jurisdictional claims in published maps and institutional affiliations. 